\title{
Multiple Crack Detection in Thick-walled Pipes Using Artificial Bee Colony Algorithm
}

\author{
Seyed Amir Banimahd ${ }^{1 *}$, Mohammad Amir Rahemi \\ ${ }^{1}$ Department of Civil Engineering, Faculty of Engineering, Ardakan University, 89518-95491 Ardakan, Iran \\ 2 International Institute of Earthquake Engineering and Seismology, 19537-14453 Tehran, Iran \\ *Corresponding author, e-mail: banimahd@ardakan.ac.ir
}

Received: 30 December 2020, Accepted: 14 March 2021, Published online: 06 April Xxxxxx 2021

\begin{abstract}
An analytical method for diagnosis of cracks in thick-walled pipes with a circular hollow section is investigated in this study. In the proposed method, the defect is assumed to be a non-leaking crack, which is modeled by a massless linear spring with infinitesimal length at the crack location. In order to find the cracks in the pipe, the vibration-based method related to the modal properties of the pipe is utilized. In the modal analysis, the mass and stiffness matrices influence the dynamic properties of the pipe. It is assumed that the mass matrix remains unchanged after the crack initiation, while the corresponding stiffness matrix changes. The stiffness matrix of a cracked element can be formulated by the finite element method with two unknown parameters: location and depth of the crack. Using the eigensolution for an undamped dynamic system to formulate the objective function yields to a complicated optimization problem, which can be solved by an iterative numerical optimization method. Among the optimization approaches, the Artificial Bee Colony $(A B C)$ algorithm is a simple and flexible technique for minimizing the objective function. In this paper, the analytical model is utilized to find the size and position of cracks in a pipe using the $A B C$ algorithm and subsequently some numerical examples are examined in order to assess the accuracy of the method. The results show that the proposed method is able to acceptably estimate the location and depth of multiple cracks in the straight pipes as well as curved ones.
\end{abstract}

Keywords

crack detection, non-leaking crack, Artificial Bee Colony algorithm, thick-walled pipe, eigensolution

\section{Introduction}

The presence of cracks in pipe structures is one of the most typical damage patterns which results in serious disadvantages to the safety and serviceability of the system. This makes the detection of the cracks in such structures so crucial. The damage detection can be achieved by nondestructive tests; however, in large-scale structures this method may become a tedious procedure. In recent years, many researchers have been working to find lowcost and reliable methods to determine the damage location and its severity and have been able to introduce some analytical techniques as an alternative method for damage detection.

After the crack initiation, dynamic characteristics of structures as well as their static behavior change. The difference between the static and dynamic responses of the healthy and cracked structures has been utilized by many researchers to develop analytical methods in order to detect the damage [1]. Analytical methods can be categorized into two categories: the deflection-based and vibration-based techniques. The deflection-based techniques are simple methods which can be carried out easily by either experimenting or performing static analyses on the damaged structure [2-4]. In the vibration-based approach, a number of studies have been carried out utilizing vibration specifications of structures such as the natural frequencies, mode shapes, modal strain energy modal curvature and flexibility, etc. [5-12]. The effectiveness of the two mentioned techniques in diagnosing damages has been studied by researchers [13]. Among these studies, many researchers have used two dynamic characteristics simultaneously for improving the efficiency of their crack detection procedure [14-16]. Others have used the experimental data to investigate the efficiency of the damage detection techniques [17]. The sensitivity of the damage identification 
results to the placement of sensors for collecting the experimental data has also been studied based on a three-level analysis in order to select the efficient location of sensors for damage detection [18].

Since the modal properties of a structure are calculated based on its mass and stiffness matrices, a proper definition of these matrices for a cracked structure is an essential part of the analytical method. The mass matrix can be assumed to remain unchanged after the crack appearance and may be represented by the consistent mass matrix in the finite element method [19]. On the contrary, the stiffness matrix changes with the initiation of the crack.

To simulate the effects of a crack on the stiffness matrix in beam-like structures, some researchers have treated the crack as a local point of flexibility, assuming that the crack affects the moment of inertia of the cross-section along the beam's length $[20,21]$. In this approach, the moment of inertia is gradually reduced with moving closer toward the crack location along the beam's longitudinal axis. This requires an excessive number of elements to simulate the crack behavior with a reasonable accuracy in a finite element approach, since each segment of the beam has a different section property. To simplify, some researchers have substituted the crack with a concentrated rotational massless spring. Thus, the section properties remain unchanged throughout the beam except for in the crack location, and hence fewer finite elements are needed to simulate the crack behavior. This method has been utilized to identify cracks in beam-like structures with a rectangular section [22-26].

Cracked beams with a circular hollow section have also been investigated by some researchers [27, 28]. Similar to the studies on beams with rectangular section, they have replaced the crack with a rotational spring connecting two segments of the pipe at the sides of the crack. Experimental data has been utilized to estimate the equivalent stiffness of the crack in thick-walled pipes and the results have been used for detecting a single crack in straight pipes. A similar research has been carried out to detect two cracks in a straight pipe [29]. In all of three studies, the successful detection of cracks is dependent on the accuracy of the experimental modelling. The variation in the boundary conditions and supports, existence of multiple cracks, and pipe indirection necessitate a fresh formulation and experimental tests for each case. The stiffness of the crack in a thick-walled hollow circular section can be obtained using the fracture mechanics [30] and analytical macro modelling [31]. The great advantage of this type of modelling is its ability to simulate the behavior of a cracked pipe without needing any experimental data.

Finding the damage in a pipe structure using the eigensolution can be transformed into a complex optimization problem [32, 33]. In recent years, iterative techniques based on the swarm intelligence have attracted considerable attention from researchers for solving complicated optimization problems. The Artificial Bee Colony (ABC) algorithm is one of the stochastic nature-inspired techniques which was developed based on the collective cooperative behavior of honey bees in finding the superlative flowers' nectar [34, 35]. The ABC algorithm has only three setting parameters in its search process which makes it simpler and more flexible compared to other known algorithms. The efficiency and competitivity of the ABC algorithm have been examined by its application to several numerical problems [36].

In this paper, the detection of non-leaking cracks in a circular hollow section is studied as an optimization problem. Here, a transverse crack is dealt with as an equivalent massless rotational spring and the obtained data from the macro element is used in lieu of the experimental data for the inverse problem. The eigensolution is utilized in order to formulate the objective function. The mass matrix, natural frequencies, and mode shapes in the objective function are considered as known values. Based on the available experimental data, some numerical examples are employed to examine the performance of the proposed method where the ABC algorithm is applied to identify the unknown crack parameters in order to detect the crack location and size.

\section{Model of the cracked pipe}

Existence of cracks in a pipe affects its mechanical properties such as mass and stiffness. A pipe can be modeled as a Timoshenko beam with four degrees of freedom: a transverse displacement in the $\xi$ direction and a rotation about $\eta$ axis at each joint (Fig. 1). To model a cracked pipe, it can be assumed that the mass of the system does not change after initiation of the crack, therefore the healthy and cracked pipes have the same mass matrices. The upper triangular terms of the mass matrix can be represented by a consistent mass matrix incorporating rotary inertia [19] as

$m=D_{1}+D_{2}$,

where 


$$
\begin{gathered}
D_{1}=\left(\rho A l_{e} / 420\right)\left[\begin{array}{cccc}
156 & 22 l_{e} & 54 & -13 l_{e} \\
& 4 l_{e}^{2} & 13 l_{e} & -3 l_{e}^{2} \\
& & 156 & -22 l_{e} \\
\text { Sym. } & & & 4 l_{e}^{2}
\end{array}\right], \\
D_{2}=\left(\rho I_{\eta} / 30 l_{e}\right)\left[\begin{array}{cccc}
36 & 3 l_{e} & -36 & 3 l_{e} \\
& 4 l_{e}^{2} & -3 l_{e} & -l_{e}^{2} \\
& & 36 & -3 l_{e} \\
\text { Sym. } & & & 4 l_{e}^{2}
\end{array}\right] .
\end{gathered}
$$

$\rho$ is the material density, $I_{\eta}$ is the moment of inertia of the pipe section about the $\eta$ axis and $l_{e}$ denotes the length of the element. As mentioned before, utilizing the distributed bending stiffness in cracked pipe modelling requires too many elements and a tedious computational effort to simulate the cracked behavior with a reasonable degree of accuracy. To surmount this problem, the cracks are considered as a massless rotational spring with an infinitesimal length at the crack location in a macro model [31] which will substantially decrease the number of elements needed to model the cracked pipe with a suitable accuracy. Hence, the macro model approach is utilized in this study to represent the stiffness matrix. In the modelling process, it is assumed that the section properties of the cracked pipe will remain unchanged along the pipe axis except at the location of the crack (Fig. 1). The fictitious rotational spring divides the pipe into two segments. Assume that $x_{c}$ is the crack location with respect to the left end of the pipe. As shown on Fig. 2, the force and displacement vectors of the cracked element can be represented by $\left[F_{1} M_{1} F_{2} M_{2}\right]$

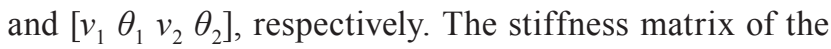
cracked element, $k$, can be derived based on the relationships between forces (moments) and displacements (rotations) of member ends.

Using the finite element method, the upper triangular stiffness matrix of a cracked element can be written as:

$$
k=\frac{1}{B_{1}}\left[\begin{array}{cccc}
1 & A_{1} & -1 & l_{e}-A_{1} \\
& C_{1} A_{1}-A_{1} & A_{1}\left(l_{e}-C_{1}\right) \\
& & 1 & -\left(l_{e}-A_{1}\right) \\
\text { Sym. } & & & l_{e}^{2}-2 A_{1} l_{e}+A_{1} C_{1}
\end{array}\right],
$$

where

$$
\begin{aligned}
& A_{1}=\left(l_{e}^{2} k_{c}+2 E I_{\eta} l_{e} \beta\right) /\left(2 l_{e} k_{c}+2 E I_{\eta}\right), \\
& B_{1}=l_{e}^{3} / 3 E I_{\eta}+l_{e} / G A_{s}-A l_{e}^{2} / 2 E I_{\eta}+\beta^{2} l_{e}^{2} / k_{c}-A \beta l_{e} / k_{c}, \\
& C_{1}=\left(2 G A_{s} k_{c} l_{e}^{2}+6 E I_{\eta} G A_{s} l_{e} \beta^{2}+6 E I_{\eta} k_{c}\right) /\left(3 G A_{s} l_{e} k_{c}+6 G A_{s} E I_{\eta} \beta\right) .
\end{aligned}
$$

$k_{c}$ is the equivalent rotational spring stiffness of the crack and $\beta$ denotes the crack position ratio equal to $x_{c} / l_{e}$. The parameters $v$ and $E$ are the Poison's ratio and modulus of elasticity of the pipe material, respectively. $G$ and $A_{s}$ are the shear modulus of elasticity and shear area, respectively. Based on the fracture mechanics theory [30] the rotational stiffness of the massless spring of the crack in a thick-walled pipe [31] is expressed by $k_{c}=1 /[2 D(a)]$, where

$D(a)=\frac{1-v^{2}}{E} \int_{-b}^{+b} \int_{0}^{\sqrt{R_{o}^{2}-\eta^{2}}-\left(R_{o}-a\right)} \frac{16}{\pi R_{o}^{8}}\left(R_{o}^{2}-\eta^{2}\right) \pi z F^{2}\left(\frac{z}{h}\right) d z d \eta$, $a=\alpha t$,

where $2 b$ is the maximum crack width $\left(2 b=2 \sqrt{R_{o}^{2}-\left(R_{0}-a\right)^{2}}\right)$ and $a$ and $t$ are the crack depth and thickness of the pipe, respectively. The crack depth ratio, $\alpha$, varies from zero for no crack to one for the leaking crack. $R_{0}$ is the outer radius of the pipe section. $h$ is defined as $h=\sqrt{R_{o}^{2}-\eta^{2}}$ and the local length of the strip is $\sqrt{R_{o}^{2}-\eta^{2}}-\left(R_{o}-a\right)$. In Eq. (5), $z$ varies from zero to the crack depth (Fig. 3). $F\left({ }^{z} / h\right)$ is given [30] as

$F\left(\frac{z}{h}\right)=\sqrt{\frac{2 h}{\pi z} \tan \frac{\pi z}{2 h}} \frac{0.923+0.199(1-\sin (\pi z / 2 h))^{4}}{\cos (\pi z / 2 h)}$.

Therefore, the stiffness of a cracked element is related to the crack parameters, $\alpha$ and $\beta$, in addition to the pipe geometry and material. Calculating the complicated integral (Eq. (5)) to obtain the equivalent spring stiffness is done numerically using the Gaussian quadrature rule, however, to facilitate the calculation for engineering practices the stiffness of the rotational spring can be represented by

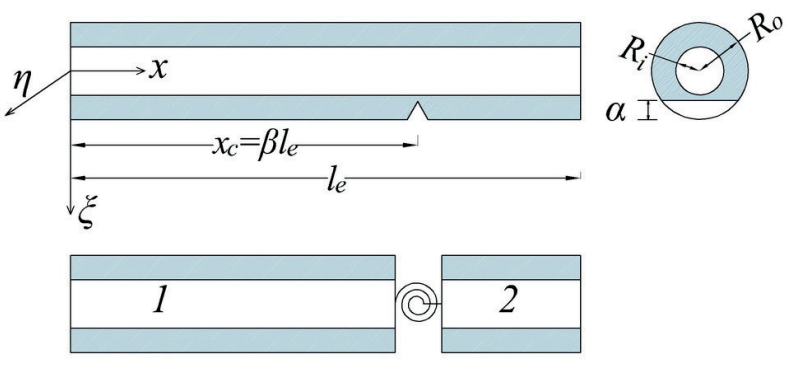

Fig. 1 Using a rotational massless spring to model the crack in the pipe

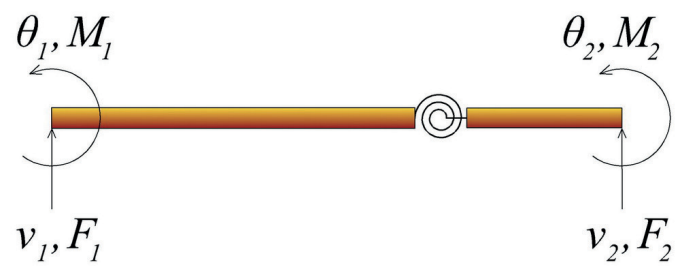

Fig. 2 The simple model of a cracked pipe 


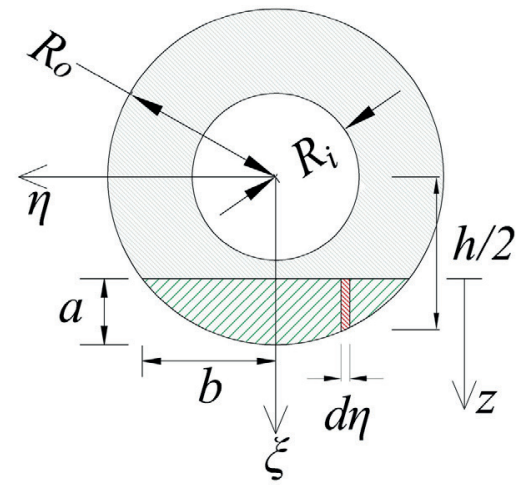

Fig. 3 Cross section of a pipe at the crack location

the following equation with a maximum relative error of $3 \%$. In this formula, $m$ and $p$ are two parameters that are given in the Appendix A for different pipe sizes per ISO 4200 pipe specifications.

$k_{c}=\frac{E}{1-v^{2}} m R_{0}^{p}$

\section{The crack detection procedure}

In this study, the dynamic characteristics of the cracked pipe is utilized for the damage detection procedure. Previous studies have shown that the results of static and dynamic analyses of a cracked pipe using the macro model are in good agreement with the experimental results [31], so in this study the analytical model is used in lieu of experimental data to verify the effectiveness of the proposed method.

The free vibration of an undamped dynamic system is presented by the following differential equation:

$M \ddot{\boldsymbol{x}}+K \boldsymbol{x}=0$,

where $M$ and $K$ are the mass and stiffness matrices of the structure, respectively, and the two over-dots indicate the second derivative with respect to time. In a cracked pipe, it is assumed that there is no change in mass after cracking, so the eigensolution of the cracked pipe can be described by:

$K^{d} \varphi^{d}-\omega_{n}^{2 d} M \varphi^{d}=0$.

The superscript $d$ denotes the damaged state of the system. $\varphi$ and $\omega_{n}$ are the matrices of the mode shapes and natural frequencies of the structure, respectively. The presence of the crack changes the stiffness of the structural element which can be represented as a function of properties of the crack and specifications of the pipe. Using finite element procedure to assemble stiffness matrix of elements [19], the stiffness matrix of the pipe structure can be obtained with respect to parameters $\alpha_{j}$ and $\beta_{j}$ as $K=K\left(\alpha_{j}, \beta_{j}\right)$ where subscript $j$ denotes the $j$ th element of the finite element model. By considering the eigensolution of the cracked pipe system, all natural frequencies and corresponding mode shapes should satisfy Eq. (9), so it is possible to rewrite it as:

$$
K^{d} \varphi_{i}^{d}-\omega_{i}^{2 d} M \varphi_{i}^{d}=0 \quad i=1, \ldots, n,
$$

where $n$ is the number of degrees of freedom of the structure which is equal to the number of its mode shapes. Since the length of the left side of Eq. (10) is zero, one can consider the following scalar function as an optimization objective function:

$$
f=\sum_{i=1}^{n}\left[\varphi_{i}^{d T}\left(K^{d}-\omega_{i}^{2 d} M\right)^{T}\left(K^{d}-\omega_{i}^{2 d} M\right) \varphi_{i}^{d}\right] .
$$

The superscript $T$ denotes the transpose of a matrix. By minimizing $f$ in Eq. (11), the stiffness matrix is obtained such that the objective function would be next to zero, so the main aim in this problem is to find the correct crack parameters, $\alpha_{j}$ and $\beta_{j} j \in[1,2, \ldots, N E]$, to minimize the objective function.

To simulate the inherent noise existing in practical measurements, the natural frequency vector can be contaminated with a predefined noise level with the following mathematical expression

$\omega^{\text {noisy }}=\omega(1+\eta \cdot \operatorname{rand}[-1,1))$

where $\eta$ is the noise level and rand denotes a uniformly distributed random number between -1 and 1 .

Exploring the optimum solution through probable candidates can be carried out by an optimization approach. Solving such complicated equation by classical techniques is very tedious, so the numerical algorithm is utilized here to find the best solution across the solution space. The ABC algorithm is a popular one which was proposed by Karaboga [34, 35]. This approach has been developed based on the intelligent behavior of honeybee swarms. The algorithm is very simple and flexible and requires fewer setting parameters compared to similar algorithms such as ant colony, genetic, etc. [36]. The ABC algorithm needs only three initial parameters to commence the optimization procedure, namely the number of food sources $(N F)$, the number of bee flights for food search without any increase in the food quality (limit), and the maximum cycle number of the search $(M C N)$. Thus, due to its robustness and fast convergence, this approach is adopted in the current study to solve the crack detection issue as an optimization problem. 
The $\mathrm{ABC}$ procedure to determine the depth and location of a crack is originated from the real behavior of the honeybees. The $\mathrm{ABC}$ algorithm uses an iterative process same as other evolutionary algorithms and the initial population $(\gamma)$ is generated haphazardly as follows:

$$
\gamma=\left[\begin{array}{llll}
\gamma_{1} & \gamma_{2} & \ldots & \gamma_{N F}
\end{array}\right]^{T}
$$

where $\gamma$ is a vector which includes both depth and location ratio of the crack and $N F$ is the number of employed bees equal to the number of food sources. The required number of employees depends on the nature of the problem, however using more employees increases the speed of finding the solution but may yield to an expensive computational process. Each artificial bee or food candidate $\gamma_{i}$ is evolutionary modified in each step of the algorithm to find the best solution and can be defined by a row vector with a length of $2 N E$ as:

$$
\gamma_{i}=\left[\alpha_{i, 1} \beta_{i, 1} \ldots \alpha_{i, j} \beta_{i, j} \ldots \alpha_{i, N E} \beta_{i, N E}\right],
$$

where $N E$ is the number of elements in the finite element model. $\alpha_{i, j}$ and $\beta_{i, j}$ denote the crack depth and location ratio of $j$ th element for $i$ th food source. In the crack detection problem, the location and severity of cracks are defined as parameters for each element, thus the number of parameters is equal to $2 N E$. The parameters $\alpha_{i, j}$ and $\beta_{i, j}$ for each food source can be generated by the following equation as:

$\alpha_{i, j}=L_{\alpha, j}+\left(U_{\alpha, j}-L_{\alpha, j}\right) \cdot \operatorname{rand}[0,1)$,

$\beta_{i, j}=L_{\beta, j}+\left(U_{\beta, j}-L_{\beta, j}\right) \cdot \operatorname{rand}[0,1)$,

$L_{j}$ and $U_{j}$ are the lower and upper band limits of the $j$ th element related to the crack properties. $\operatorname{rand}[0,1]$ is a random number between 0 and 1 . The subscript $j$ represents the variable number $(j=1,2, \ldots, N E)$ and the subscript $i$ denotes the solution or the food source number $(i=1,2, \ldots, N F)$.

In the first run, some random solutions (food source) are generated and assigned to each bee. To find a probable better solution, every employed bee searches the neighborhood of its currently related food source. The new solution could be given as:

$\boldsymbol{\gamma}_{i, j}^{\text {new }}=\boldsymbol{\gamma}_{i, j}+\left(\boldsymbol{\gamma}_{i, j}-\boldsymbol{\gamma}_{k, j}\right) \cdot \operatorname{rand}[-1,1] \quad k \neq i$,

where $k$ is determined randomly and it also differs from $i$ to ensure that the step size has some upgrading in solving the optimization problem. rand $[-1,1]$ is a random number in the interval $[-1,1]$. The employed bees share the information of searched solution space in the hive by the waggle dance. The fitness value of $i$ th food source is obtained by the following equation:

$$
\operatorname{Fit}\left(\gamma_{i}\right)=1 /\left(1+F\left(\gamma_{i}\right)\right)
$$

And the probability of each food source is obtained as:

$$
P\left(\gamma_{i}\right)=F i t\left(\gamma_{i}\right) / \sum_{k=1}^{N F} \operatorname{Fit}\left(\gamma_{k}\right) \text {. }
$$

Different schemes can be used to calculate the probability value of the food source. One common formulation for this purpose is:

$P\left(\gamma_{i}\right)=0.9 F i t\left(\gamma_{i}\right) / \max \operatorname{Fit}\left(\gamma_{i}\right)+0.1$,

which is used in this study to calculate the probability of each candidate. Considering the greedy selection, the superior food source has the greater chance to be selected for the next search. If the quality of a food source cannot be further improved through a predefined number of searches (limit), the current location will be abandoned and replaced by a new solution according to Eq. (15). The process will iterate until it reaches the max cycle number $(M C N)$. The best food source during the iteration is memorized and reported at the end as the best solution.

\section{Examples}

In this section, the robustness and effectiveness of the ABC algorithm to detect cracks in pipes using the macro model are shown by two numerical examples. Thick-walled pipes with a circular hollow section are considered for this purpose. The cracks are modeled as non-leaking type. The first example is a straight pipe whose experimental data is available in ref [29]. In the second example, a non-straight pipe is examined in order to show the ability of the proposed approach in analytically finding existing cracks in a nonstraight pipe. In each example, the crack properties, depth, and location are found using the $\mathrm{ABC}$ algorithm by minimizing the appropriate objective function.

\subsection{The straight pipe}

Here, two examples are considered based on the cracked pipe's material either made of mild steel or aluminum. The related experimental data can be found in ref [29]. Among several water pressure conditions tested in the experiments reported in these references, the pressure equal to $0.491 \mathrm{MPa}$ is selected. Both ends of the pipe were closed by a cap and one end was connected to a hydraulic pump for creating the inner water pressure. The cracks 
were generated by a wire-cut machine with a wire diameter of $0.15 \mathrm{~mm}$. The natural frequencies were measured by an accelerometer fixed by wax on top of the pipe $0.20 \mathrm{~m}$ away from one of the supports. The Young modulus of elasticity for aluminum and mild steel pipes was obtained through the measurement of their second natural frequency using the following formula:

$E=\frac{\omega_{2}{ }^{2} m L^{4}}{16 \pi^{4} I_{\eta}}$.

Both aluminum and steel pipes were simply supported at their ends as shown in Fig. 4(a). The geometry and material properties of the mild steel and aluminum pipes are shown in Table 1.

Four different scenarios of the crack occurrence are examined here based on the experimental data. The crack properties for each scenario are presented in Table 2. Two first scenarios contain only one crack in the first quarter of the pipes' length while the others have two simultaneous cracks one in the first quarter and one in the second quarter of the pipes' length.

In order to determine the suitable number of finite elements required to accurately model the pipes, a convergence test has been used for computing their natural frequencies [31].

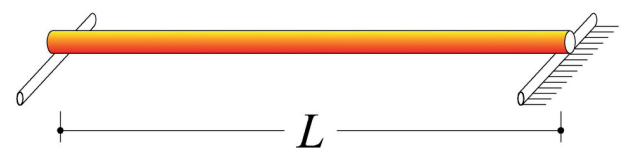

(a)

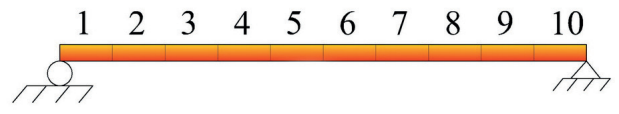

(b)

Fig. 4 (a) The cracked simply supported pipe configuration and (b) Finite element model of the cracked pipe

Table 1 Geometry and material properties of the pipes

\begin{tabular}{lccccc}
\hline $\begin{array}{l}\text { Pipe } \\
\text { Material }\end{array}$ & $\begin{array}{c}L \\
(\mathrm{~cm})\end{array}$ & $\begin{array}{c}R_{0} \\
(\mathrm{~mm})\end{array}$ & $\begin{array}{c}R_{i} \\
(\mathrm{~mm})\end{array}$ & $\begin{array}{c}\mathrm{E}_{\text {water-filled }} \\
(\mathrm{GPa})\end{array}$ & $\begin{array}{c}\rho \\
\left(\mathrm{Kg} / \mathrm{m}^{3}\right)\end{array}$ \\
\hline Aluminum & 87 & 16.50 & 10.00 & 62.44 & 2645 \\
Mild steel & 80 & 16.00 & 9.75 & 179.54 & 7860 \\
\hline
\end{tabular}

Table 2 Crack properties in the steel and aluminum pipes

\begin{tabular}{lcccc}
\hline & \multicolumn{2}{c}{ One crack } & \multicolumn{2}{c}{ Two cracks } \\
Scenarios number & 1 & 2 & 3 & 4 \\
\hline$x_{c 1} / L$ & 0.207 & 0.403 & 0.207 & 0.250 \\
$a_{1} / t$ & 0.191 & 0.508 & 0.191 & 0.203 \\
$x_{c 2} / L$ & - & - & 0.350 & 0.403 \\
$a_{2} / t$ & - & - & 0.381 & 0.508 \\
\hline
\end{tabular}

Using ten elements has provided an acceptable accuracy, based on the experimental measurement data, with a maximum error of $3 \%$ for the pipe with internal pressure of $0.491 \mathrm{Mpa}$. So, to model the cracked pipe, a finite element model with ten elements with equal lengths is utilized here as shown in Fig. 4(b). The length of each element for the aluminum and mild steel pipes are $8.70 \mathrm{~cm}$ and $8.00 \mathrm{~cm}$, respectively. Considering the crack depth and location as unknown parameters for each element, the damage detection is practically converted into an optimization problem with 20 parameters which have to be found. The parameters are limited to the real values such that the crack depth ratio $(a / t)$ and the crack location ratio $\left(x_{c} / l_{e}\right)$ vary from 0 to 1 . The crack depth ratio is equal to zero when no crack is appeared in the element, while the values greater than one mean a leaking crack which is not permissible in this study. The value of the crack location ratio also varies from 0 to 1 corresponding to the start and end of an element, respectively. Therefore, the solution for the optimization problem in this example is a vector with a length of 20 , comprising of crack depth and location ratios of all pipe elements. A predetermined number of vectors (bees) with a length of 20 is utilized here to find the solution. As stated before, according to the artificial bee colony algorithm, the considered vectors are intelligently modified until the solution vector is obtained. Food source number is a preset parameter of the $\mathrm{ABC}$ algorithm and can be set based on the complexity of the problem. The more complex the nature of a problem is, the higher food source number is required to efficiently find the solution. The number of food sources affects the speed of convergence of the ABC algorithm, however, an in-depth assessment of this subject is out of the scope of this study. For the current example, a value of 20 has been selected for the number of food sources and the number of the bees with a quick discussion presented at the end of this example. The maximum number of iterations for changing the set of vectors (i.e., the number of the bee flights to the food sources) is ruled by the maximum cycle number $(M C N)$ which is set to be 3000 in this example to ensure the cracks are detected correctly.

Fig. 5(a) and (b) show the results of the proposed procedure to find the crack location and depth ratios for each structural element using the $\mathrm{ABC}$ algorithm in the case of one crack in aluminum and steel pipes, respectively. As can be seen, the predicted crack location as well as the crack depth are in good agreement with those of the tested pipes with a minimal error for both scenarios. The results of the crack identification method in the case of two simultaneous 


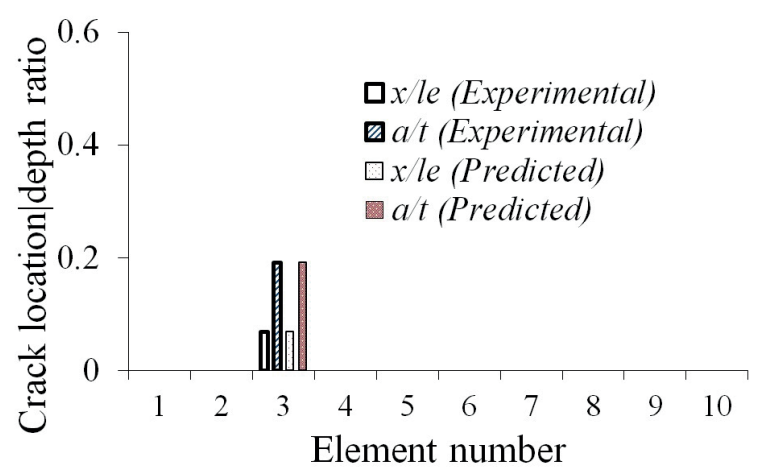

(a)

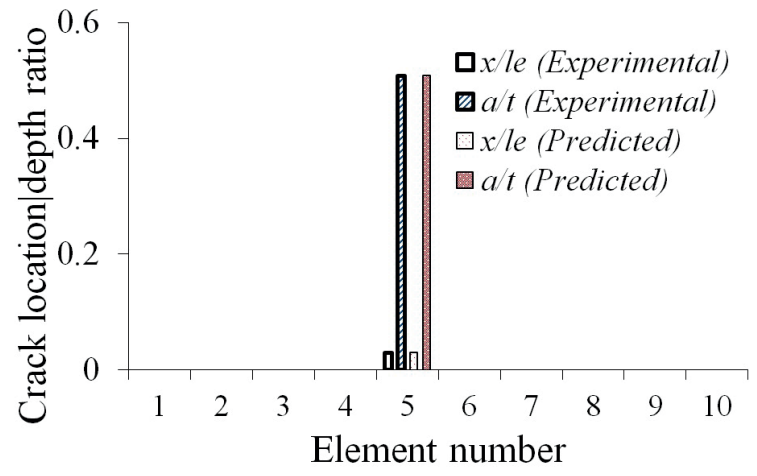

(b)

Fig. 5 Detection of one crack in a straight pipe: (a) Aluminum pipe and (b) Steel pipe

cracks are depicted in Fig. 6(a) and (b) for the aluminum and mild steel pipes, respectively. The results show that the crack location and depth can be obtained for the two considered scenarios with a reasonable accuracy.

The existing error in the results of the proposed procedure can be categorized into two types: the error of modeling related to the discretization in the finite element approach which can be reduced by increasing the number of elements; and the error pertaining to the noise effect generally observed in practical measurements. In order to deal with the latter and to better simulate the realistic conditions, a level of noise can be added to the terms of the mode shapes. Fig. 7 shows the convergence history of the $\mathrm{ABC}$ algorithm for 3000 iterations with different noise levels for the first scenario using 20 bees. As shown in the figure, when the noisy data is used, the number of iterations required for crack detection increases. This figure shows that although the convergence rate reduces in presence of the noise in the experimental data, the proposed method is still able to detect the depth and location of the cracks with an acceptable accuracy.

The detected crack parameters for a noise-free set of data are shown in Table 3 in different stages of the process. The horizontal axis depicts the pipe element number while the vertical axis shows the crack location ratio

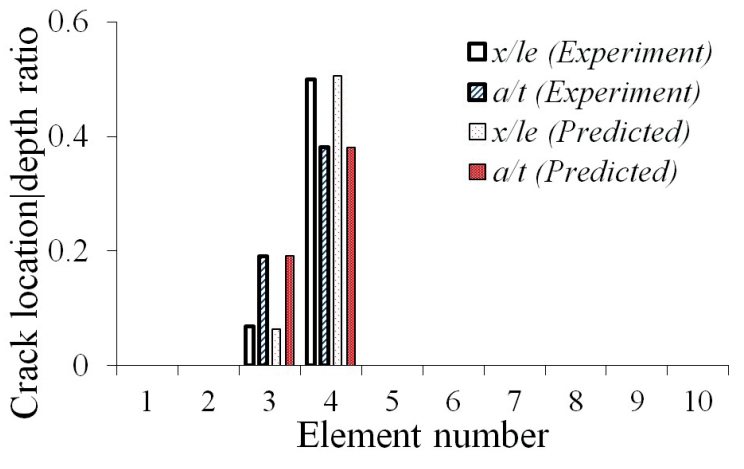

(a)

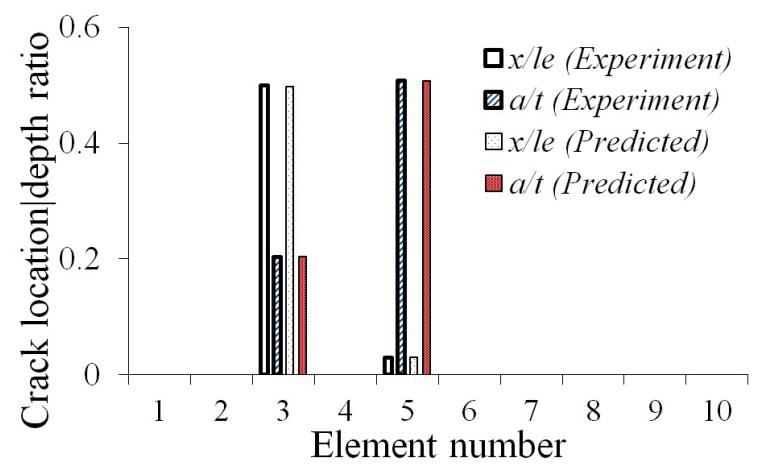

(b)

Fig. 6 Detection of two cracks in a straight pipe: (a) Aluminum pipe and (b) Steel pipe

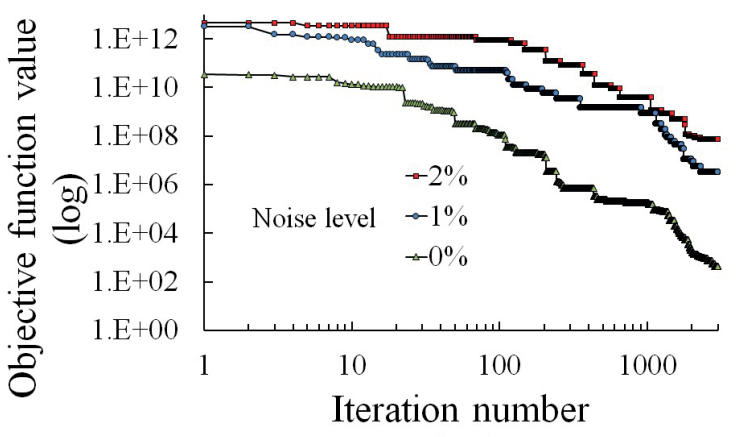

$(\log )$

Fig. 7 Effect of noisy data in crack detection convergence rate

(light-color bars) and crack depth ratio (dark-color bars). As it can be seen that as the iterations proceed, the crack depth ratio concentrates on the defective element and converges to zero for other elements. If no crack depth ratio appears for an element with a nonzero value for its crack location ratio, it means that the element has no crack.

Although there is some error in estimating the crack location and depth ratios in both numerical examples, it is generally low and negligible and the proposed method is able to robustly detect the cracks in the pipe. To enhance the accuracy of the crack identification, increasing the number of elements in the finite element model can be suggested as a simple solution. 
Table 3 Crack properties variation in different stages of iterative procedure (scenario 1)

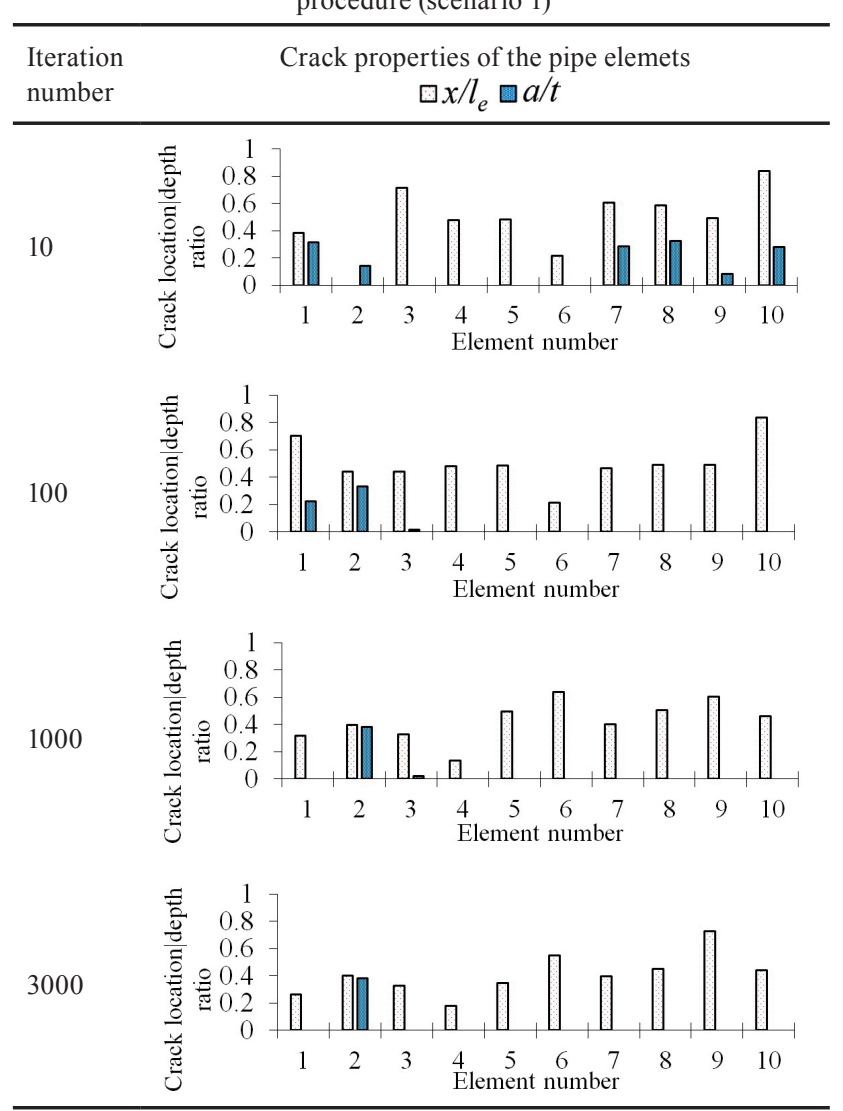

As explained before, the determination of the number of employed bees utilized for finding the food source is in itself an optimization problem. There is an optimum number of bees for each problem, which provides a suitable convergence speed with a reasonable computational effort. The effect of the number of bees on the convergence speed of the objective function is shown in Fig. 8 for the first scenario. As the number of bees increases, the convergence happens at a higher rate, but requires more computational effort. As it can be seen, the increase in the bee population from 10 to 20 has a dramatic effect on the convergence speed, but it is not as efficient when it is increased from 20 to 80 . The optimum population of bees can vary from one problem to another, so it is advisable to initially perform a sensitivity analysis on this parameter to find the most cost-effective value to use throughout the optimization process.

\subsection{The non-straight pipe}

In the previous example, it was shown that the numerical simulation of the test results can be used as successfully as the real tests even when noise was added to the numerical results, so in this example a numerical model is used in lieu of real test results. Here, a non-straight steel pipe with multiple cracks is considered as shown in Fig. 9(a). Two crack scenarios are assumed according to Table 4. The pipe properties and pressure condition are the same as described in the preceding example. The finite element model of the pipe is depicted in Fig. 9(b) and the length of elements is tabulated in Table 5. The number of elements

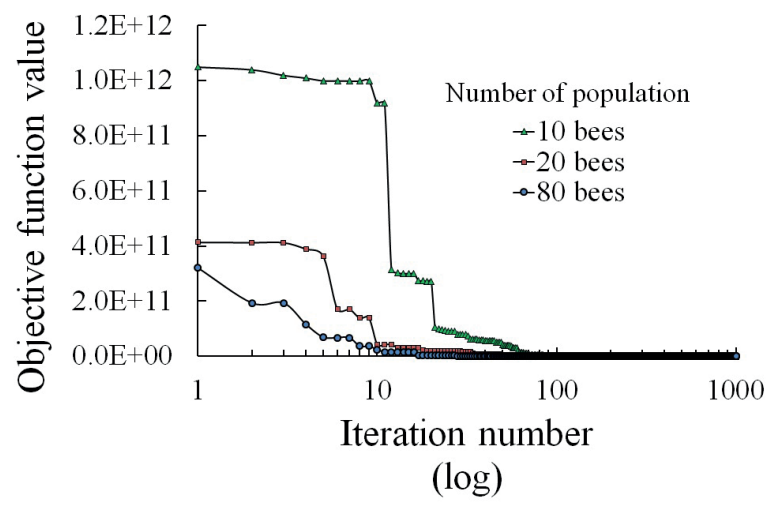

Fig. 8 The effect of the bee population on the convergence speed (Scenario 1)

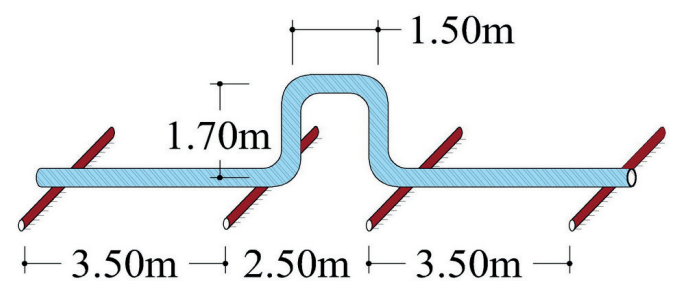

(a)

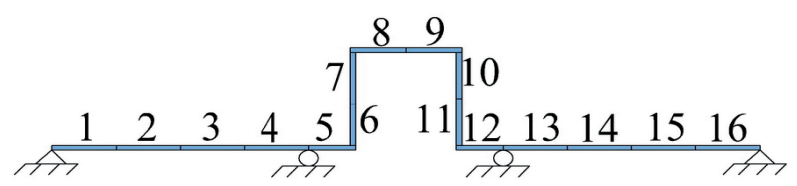

(b)

Fig. 9 (a) The non-straight pipe and (b) Finite element model of the cracked pipe

Table 4 Considered crack properties in the non-straight pipe

\begin{tabular}{lcc}
\hline Scenario number & 1 & 2 \\
\hline$x_{3} / L$ & 0.30 & 0.42 \\
$a_{3} / t$ & 0.15 & 0.35 \\
$x_{8} / L$ & 0.85 & - \\
$a_{8} / t$ & 0.35 & - \\
$x_{12} / L$ & 0.10 & - \\
$a_{12} / t$ & 0.80 & - \\
$x_{16} / L$ & 0.32 & 0.50 \\
$a_{16} / t$ & 0.15 & 0.25 \\
\hline
\end{tabular}

Table 5 Length of elements (cm)

\begin{tabular}{lcccc}
\hline Element & $1-4$, & 6,7, & 5, & 8, \\
number & $12-16$ & 10,11 & 12 & 9 \\
\hline Length & 87.5 & 85 & 50 & 75 \\
\hline
\end{tabular}


can be increased easily to enhance the accuracy of the finite element model for damage detection, but 16 seems to be sufficient for this example. In the first scenario, the cracks are assumed to be occurring in elements \#3,8,12, and 16, while in the second scenario, only elements \#3 and 16 are assumed to have cracks. Here, 64 artificial bees are utilized for the $\mathrm{ABC}$ algorithm. As described before, increasing the number of bees improves the search quality but results in an increase in the fly time as well. Also, presence of the noise in the experimental data reduces the convergence speed. For example, for Scenario 1, the convergence occurs approximately after 2000, 4000 and 5000 steps for noise levels of $0 \%, 1 \%$, and $2 \%$, respectively.

In Fig. 10 are illustrated the results of the damage detection procedure for the non-straight hollow-section pipe in the two different scenarios. The results show that the numerically assumed cracks are predicted by the proposed method with a reasonable accuracy. This example also shows the ability of the proposed method in finding multiple cracks without any need to measurement-based verification of the crack stiffness.

\section{Conclusions}

In this paper, a method was presented based on the $\mathrm{ABC}$ algorithm to detect the location and depth of cracks in pipes with a circular hollow section using their modal properties. A macro element which simulates a crack in a thick-walled pipe as a rotational massless spring was utilized to calculate the stiffness matrix of the cracked pipe. The consistent mass matrix incorporating rotary inertia were also used. In order to formulate an objective function, the eigensolution of an undamped dynamic system representing the cracked pipe was utilized. The $\mathrm{ABC}$ algorithm was employed to minimize the objective function to

\section{References}

[1] Doebling, S. W., Farrar, C. R., Prime, M. B., Shevitz, D. W. "Damage identification and health monitoring of structural and mechanical systems from changes in their vibration characteristics: A literature review", Los Alamos National Laboratory, Los Alamos, NM, USA, Rep. LA-13070-MS, 1996. https://doi.org/10.2172/249299

[2] Naik, S. S. "Crack Detection in Pipes Using Static Deflection Measurements", Journal of the Institution of Engineers, 93(3), pp. 209-215, 2012. https://doi.org/10.1007/s40032-012-0027-z

[3] Caddemi, S., Morrasi, A. "Crack detection in elastic beams by static measurements", International Journal of Solids and Structures, 44, pp. 5301-5315, 2006.

https://doi.org/10.1016/j.ijsolstr.2006.12.033

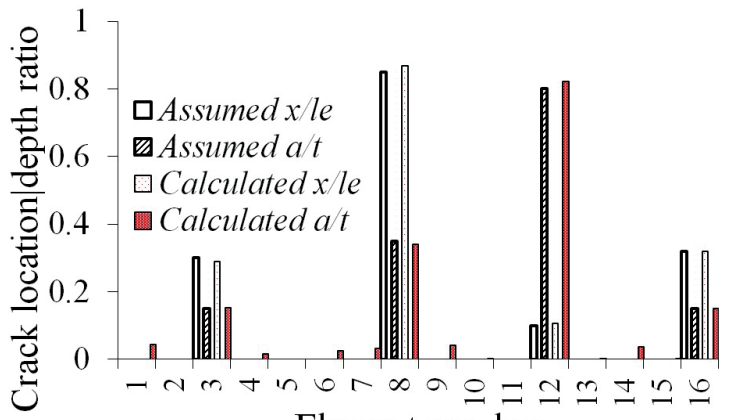

Element number

(a)

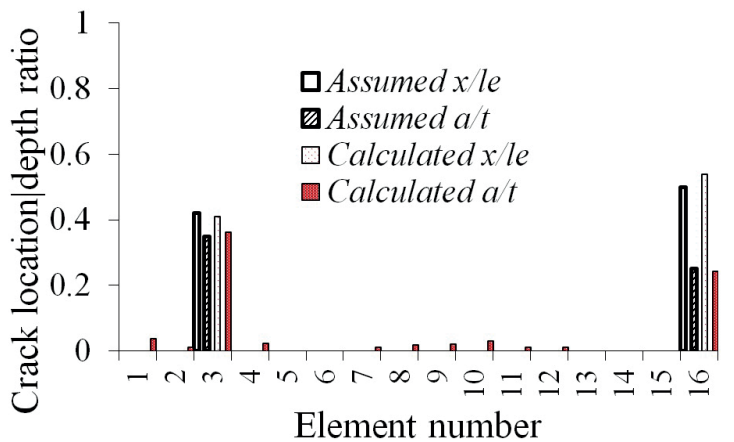

(b)

Fig. 10 Detection of cracks in a non-straight pipe: (a) Scenario 1 and (b) Scenario 2

identify the crack location and depth. Numerical examples were studied to verify feasibility and accuracy of the presented approach. The crack detection method was carried out for the straight and non-straight pipes under two different scenarios to consider various conditions of crack occurrence. The results indicated that the proposed method was able to detect the location and depth of the cracks with an acceptable accuracy. Moreover, it was shown that the cracks could be diagnosed without using the measurement-based validation of the crack stiffness.

[4] Kourehli, S. S., Bagheri, A., Amiri, G. G., Ghafory-Ashtiany, M. "Structural damage detection using incomplete modal data and incomplete static response", KSCE Journal of Civil Engineering, 17, pp. 216-223, 2013. https://doi.org/10.1007/s12205-012-1864-2

[5] Fan, W., Qiao, P. "Vibration-based Damage Identification Methods: A Review and Comparative Study", Structural Health Monitoring, 10(1), pp. 83-111, 2011. https://doi.org/10.1177/1475921710365419

[6] Salawu, O. S. "Detection of structural damage through changes in frequency: a review", Engineering Structures, 19, pp. 718-723, 1997.

https://doi.org/10.1016/S0141-0296(96)00149-6 
[7] Hsieh, K. H., Halling, M. W., Barr, P., Robinson, M. J. "Structural Damage Detection Using Dynamic Properties Determined from Laboratory and Field Testing", Journal of Performance of Constructed Facilities, 22(4), pp. 238-244, 2008. https://doi.org/10.1061/(ASCE)0887-3828(2008)22:4(238)

[8] Shi, Z. Y., Law, S. S., Zhang, L. M. "Structural Damage Detection from Modal Strain Energy Change", Journal of Engineering Mechanics, 126(12), pp. 1216-1223, 2000. https://doi.org/10.1061/(ASCE)0733-9399(2000)126:12(1216)

[9] Sha, G., Radzieński, M., Cao, M., Ostachowicz, W. "A novel method for single and multiple damage detection in beams using relative natural frequency changes", Mechanical Systems and Signal Processing, 132, pp. 335-352, 2019. https://doi.org/10.1016/j.ymssp.2019.06.027

[10] Lopez-Pacheco, M., Morales-Valdez, J., Yu, W. "Frequency domain CNN and dissipated energy approach for ddamage detection in building structures", Soft Computing, 24, pp. 15821-15840, 2020. https://doi.org/10.1007/s00500-020-04912-w

[11] Khatir, S., Abdel Wahab, M., Boutchicha, D., Khatir, T. "Structural health monitoring using modal strain energy damage indicator coupled with teaching-learning-based optimization algorithm and isogoemetric analysis", Journal of Sound and Vibration, 448, pp. 230-246, 2019.

https://doi.org/10.1016/j.jsv.2019.02.017

[12] Riasat Azim, M., Gül, M. "Damage Detection of Steel-Truss Railway Bridges Using Operational Vibration Data", Journal of Structural Engineering, 146(3), Article No. 04020008, 2020. https://doi.org/10.1061/(ASCE)ST.1943-541X.0002547

[13] Kourehli, S. S. "Damage Diagnosis of Structures Using Modal Data and Static Response", Periodica Polytechnica Civil Engineering, 61(1), pp. 135-145, 2017.

https://doi.org/10.3311/PPci.7646

[14] Rasouli, A., Ghodrati Amiri, G., Kheyroddin, A., GhaforyAshtiany, M., Kourehli, S. S. "A new method for damage prognosis based on incomplete modal data via an evolutionary algorithm", European Journal of Environmental and Civil Engineering, 18(3), pp. 253-270, 2014.

https://doi.org/10.1080/19648189.2014.881758

[15] Seyedpoor, S. M. "A two-stage method for structural damage detection using a modal strain energy-based index and particle swarm optimization", International Journal of Non-Linear Mechanics, 47, pp. 1-8, 2012.

https://doi.org/10.1016/j.ijnonlinmec.2011.07.011

[16] Altunışık, A. C., Okur, F. Y., Karaca, S., Kahya, V. "Vibration-based damage detection in beam structures with multiple cracks: modal curvature vs. modal flexibility methods", Nondestructive Testing and Evaluation, 34(1), pp. 33-53, 2019. https://doi.org/10.1080/10589759.2018.1518445

[17] Bayer, J., Král, J., Urushadze, S. "Localization of Simulated Damage on a Steel Beam from Random Vibrations", Periodica Polytechnica Civil Engineering, 62(1), pp. 112-116, 2018. https://doi.org/10.3311/PPci.10625

[18] Blachowski, B. "Modal Sensitivity Based Sensor Placement for Damage Identification Under Sparsity Constraint", Periodica Polytechnica Civil Engineering, 63(2), pp. 432-445, 2019. https://doi.org/10.3311/PPci.13888
[19] Bathe, K.-J. "Finite Element Procedures", Prentice-Hall, Upper Saddle River, NJ, USA, 1996.

[20] Yang, X. F., Swamidas, A. S. J., Seshadri, R. "Crack identification in vibrating beams using the energy method", Journal of Sound and Vibration, 244, pp. 339-357, 2001. https://doi.org/10.1006/jsvi.2000.3498

[21] Swamidas, A. S. J., Yang, X., Seshadri, R. "Identification of Cracking in Beam Structures Using Timoshenko and Euler Formulations", Journal of Engineering Mechanics, 130(11), pp. 1297-1308, 2004. https://doi.org/10.1061/(ASCE)0733-9399(2004)130:11(1297)

[22] Ostachowicz, W. M., Krawczuk, M. "Analysis of the effect of cracks on the natural frequencies of a cantilever beam", Journal of Sound and Vibration, 150, pp. 191-201, 1991.

https://doi.org/10.1016/0022-460X(91)90615-Q

[23] Behzad, M., Ghadami, A., Maghsoodi, A., Hale, J. M. "Vibration based algorithm for crack detection in cantilever beam containing two different types of cracks", Journal of Sound and Vibration, 332, pp. 6312-6320, 2013. https://doi.org/10.1016/j.jsv.2013.07.003

[24] Maghsoodi, A., Ghadami, A., Mirdamadi, H. R. "Multiple-crack damage detection in multi-step beams by a novel local flexibilitybased damage index", Journal of Sound and Vibration, 332, 294305, 2013.

https://doi.org/10.1016/j.jsv.2012.09.002

[25] Mehrjoo, M., Khaji, N., Ghafory-Ashtiany, M. "New Timoshenkocracked beam element and crack detection in beam-like structures using genetic algorithm", Inverse Problems in Science and Engineering, 22(3), pp. 359-382, 2014. https://doi.org/10.1080/17415977.2013.788170

[26] Ghannadi, P., Kourehli, S. S., Noori, M., Altabey, W. A. "Efficiency of grey wolf optimization algorithm for damage detection of skeletal structures via expanded mode shapes", Advances in Structural Engineering, 23(13), pp. 2850-2865, 2020. https://oi.org/10.1177/1369433220921000

[27] Murigendrappa, S. M., Maiti, S. K., Srirangarajan, H. R. "Experimental and theoretical study on crack detection in pipes filled with fluid", Journal of Sound and Vibration, 270, pp. 10131032, 2004. https://doi.org/10.1016/S0022-460X(03)00198-6

[28] Naniwadekar, M. R., Naik, S. S., Maiti, S. K. "On prediction of crack in different orientations in pipe using frequency-based approach", Mechanical Systems and Signal Processing, 22, pp. 693-708, 2008. https://doi.org/10.1016/j.ymssp.2007.09.007

[29] Murigendrappa, S. M., Maiti, S. K., Srirangarajan, H. R. "Frequencybased experimental and theoretical identification of multiple cracks in straight pipes filled with fluid", NDT \& E International, 37, pp. 431-438, 2004. https://doi.org/10.1016/j.ndteint.2003.11.009

[30] Tada, H., Paris, P. C., Irwin, G. R. "The Stress Analysis of Cracks Handbook", ASME Press, New York, NY, USA, 2000. https://doi.org/10.1115/1.801535

[31] Banimahd, A. "Development of Finite Element Models for Predicting the Mechanical Behavior of the Cracked Pipe", KSCE Journal of Civil Engineering, 22, pp. 5035-5045, 2018. https://doi.org/10.1007/s12205-017-1361-8 
[32] Ding, Z., Yao, R., Li, J., Lu, Z. "Structural damage identification based on modified Artificial Bee Colony algorithm using modal data", Inverse Problems in Science and Engineering, 26(3), pp. 422442, 2018.

https://doi.org/10.1080/17415977.2017.1310855

[33] Wei, Z., Liu, J., Lu, Z. "Structural damage detection using improved particle swarm optimization", Inverse Problems in Science and Engineering, 26(6), pp. 792-810, 2018. https://doi.org/10.1080/17415977.2017.1347168

[34] Karaboga, D. "An idea based on honey bee swarm for numerical optimization", Erciyes University, Engineering Faculty, Computer Engineering Department, Kayseri, Turkey, Rep. TR06, 2005.
[35] Karaboga, D., Basturk, B. "A powerful and efficient algorithm for numerical function optimization: artificial bee colony $(\mathrm{ABC})$ algorithm", Journal of Global Optimization, 39, pp. 459-471, 2007. https://doi.org/10.1007/s10898-007-9149-X

[36] Karaboga, D., Akay, B. "A comparative study of Artificial Bee Colony algorithm", Applied Mathematics and Computation, 214, pp. 108-132, 2009.

https://doi.org/10.1016/j.amc.2009.03.090 


\section{Appendix A}

Table 6 Pipe paremeters to calculate the rotational stiffness of the crack

\begin{tabular}{|c|c|c|c|c|c|c|c|c|}
\hline \multirow{3}{*}{$\begin{array}{l}\text { Pipe's wall } \\
\text { thickness }(\mathrm{mm})\end{array}$} & \multicolumn{8}{|c|}{$a / t$} \\
\hline & \multicolumn{2}{|c|}{0.25} & \multicolumn{2}{|c|}{0.50} & \multicolumn{2}{|c|}{0.75} & \multicolumn{2}{|c|}{1.00} \\
\hline & $m$ & $p$ & $m$ & $p$ & $m$ & $p$ & $m$ & $p$ \\
\hline 0.5 & $9.53 \mathrm{E}+02$ & 5.49 & $1.70 \mathrm{E}+02$ & 5.49 & $6.25 \mathrm{E}+01$ & 5.48 & $3.08 \mathrm{E}+01$ & 5.47 \\
\hline 0.6 & $6.04 \mathrm{E}+02$ & 5.49 & $1.08 \mathrm{E}+02$ & 5.49 & $3.96 \mathrm{E}+01$ & 5.48 & $1.96 \mathrm{E}+01$ & 5.48 \\
\hline 0.8 & $2.95 \mathrm{E}+02$ & 5.49 & $5.27 \mathrm{E}+01$ & 5.49 & $1.94 \mathrm{E}+01$ & 5.48 & $9.58 \mathrm{E}+00$ & 5.48 \\
\hline 1 & $1.69 \mathrm{E}+02$ & 5.49 & $3.04 \mathrm{E}+01$ & 5.49 & $1.12 \mathrm{E}+01$ & 5.48 & $5.55 \mathrm{E}+00$ & 5.47 \\
\hline 1.2 & $1.07 \mathrm{E}+02$ & 5.49 & $1.93 \mathrm{E}+01$ & 5.49 & $7.11 \mathrm{E}+00$ & 5.48 & $3.53 \mathrm{E}+00$ & 5.47 \\
\hline 1.4 & $7.32 \mathrm{E}+01$ & 5.49 & $1.32 \mathrm{E}+01$ & 5.49 & $4.88 \mathrm{E}+00$ & 5.48 & $2.43 \mathrm{E}+00$ & 5.47 \\
\hline 1.6 & $5.23 \mathrm{E}+01$ & 5.49 & $9.40 \mathrm{E}+00$ & 5.49 & $3.47 \mathrm{E}+00$ & 5.48 & $1.72 \mathrm{E}+00$ & 5.48 \\
\hline 1.8 & $3.89 \mathrm{E}+01$ & 5.50 & $6.99 \mathrm{E}+00$ & 5.49 & $2.58 \mathrm{E}+00$ & 5.49 & $1.28 \mathrm{E}+00$ & 5.48 \\
\hline 2 & $2.99 \mathrm{E}+01$ & 5.50 & $5.37 \mathrm{E}+00$ & 5.49 & $1.98 \mathrm{E}+00$ & 5.49 & $9.80 \mathrm{E}-01$ & 5.48 \\
\hline 2.3 & $2.11 \mathrm{E}+01$ & 5.49 & $3.80 \mathrm{E}+00$ & 5.49 & $1.40 \mathrm{E}+00$ & 5.48 & $6.97 \mathrm{E}-01$ & 5.48 \\
\hline 2.6 & $1.55 \mathrm{E}+01$ & 5.50 & $2.78 \mathrm{E}+00$ & 5.49 & $1.02 \mathrm{E}+00$ & 5.49 & $5.07 \mathrm{E}-01$ & 5.48 \\
\hline 2.9 & $1.18 \mathrm{E}+01$ & 5.50 & $2.12 \mathrm{E}+00$ & 5.49 & 7.83E-01 & 5.49 & $3.89 \mathrm{E}-01$ & 5.48 \\
\hline 3.2 & $9.21 \mathrm{E}+00$ & 5.50 & $1.65 \mathrm{E}+00$ & 5.49 & $6.07 \mathrm{E}-01$ & 5.49 & $3.00 \mathrm{E}-01$ & 5.49 \\
\hline 3.6 & $6.87 \mathrm{E}+00$ & 5.50 & $1.23 \mathrm{E}+00$ & 5.49 & 4.54E-01 & 5.49 & $2.25 \mathrm{E}-01$ & 5.49 \\
\hline 4 & $5.26 \mathrm{E}+00$ & 5.50 & $9.41 \mathrm{E}-01$ & 5.50 & $3.45 \mathrm{E}-01$ & 5.49 & $1.70 \mathrm{E}-01$ & 5.49 \\
\hline 4.5 & $3.93 \mathrm{E}+00$ & 5.50 & 7.03E-01 & 5.49 & $2.58 \mathrm{E}-01$ & 5.49 & $1.28 \mathrm{E}-01$ & 5.49 \\
\hline 5 & $3.02 \mathrm{E}+00$ & 5.50 & $5.40 \mathrm{E}-01$ & 5.50 & $1.98 \mathrm{E}-01$ & 5.49 & $9.80 \mathrm{E}-02$ & 5.49 \\
\hline 5.4 & $2.49 \mathrm{E}+00$ & 5.50 & $4.46 \mathrm{E}-01$ & 5.49 & $1.64 \mathrm{E}-01$ & 5.49 & 8.11E-02 & 5.49 \\
\hline 5.6 & $2.27 \mathrm{E}+00$ & 5.50 & $4.06 \mathrm{E}-01$ & 5.50 & $1.49 \mathrm{E}-01$ & 5.49 & 7.38E-02 & 5.49 \\
\hline 6.3 & $1.69 \mathrm{E}+00$ & 5.50 & $3.03 \mathrm{E}-01$ & 5.50 & 1.11E-01 & 5.49 & $5.50 \mathrm{E}-02$ & 5.49 \\
\hline 7.1 & $1.26 \mathrm{E}+00$ & 5.50 & $2.25 \mathrm{E}-01$ & 5.50 & $8.26 \mathrm{E}-02$ & 5.49 & $4.08 \mathrm{E}-02$ & 5.49 \\
\hline 8 & $9.32 \mathrm{E}-01$ & 5.50 & $1.67 \mathrm{E}-01$ & 5.50 & $6.14 \mathrm{E}-02$ & 5.49 & $3.03 \mathrm{E}-02$ & 5.49 \\
\hline 8.8 & 7.35E-01 & 5.50 & $1.32 \mathrm{E}-01$ & 5.50 & $4.84 \mathrm{E}-02$ & 5.49 & 2.39E-02 & 5.49 \\
\hline 10 & $5.34 \mathrm{E}-01$ & 5.50 & $9.56 \mathrm{E}-02$ & 5.50 & $3.52 \mathrm{E}-02$ & 5.49 & $1.74 \mathrm{E}-02$ & 5.49 \\
\hline 11 & $4.21 \mathrm{E}-01$ & 5.50 & $7.56 \mathrm{E}-02$ & 5.49 & $2.78 \mathrm{E}-02$ & 5.49 & $1.38 \mathrm{E}-02$ & 5.49 \\
\hline 12.5 & $3.07 \mathrm{E}-01$ & 5.50 & $5.51 \mathrm{E}-02$ & 5.49 & $2.03 \mathrm{E}-02$ & 5.49 & $1.01 \mathrm{E}-02$ & 5.49 \\
\hline 14.2 & $2.23 \mathrm{E}-01$ & 5.50 & $4.02 \mathrm{E}-02$ & 5.49 & $1.49 \mathrm{E}-02$ & 5.49 & $7.41 \mathrm{E}-03$ & 5.49 \\
\hline 16 & $1.66 \mathrm{E}-01$ & 5.50 & $3.00 \mathrm{E}-02$ & 5.49 & $1.11 \mathrm{E}-02$ & 5.49 & $5.55 \mathrm{E}-03$ & 5.49 \\
\hline 17.5 & $1.33 \mathrm{E}-01$ & 5.50 & $2.41 \mathrm{E}-02$ & 5.49 & $8.94 \mathrm{E}-03$ & 5.49 & $4.47 \mathrm{E}-03$ & 5.48 \\
\hline 20 & $9.56 \mathrm{E}-02$ & 5.50 & $1.74 \mathrm{E}-02$ & 5.49 & $6.47 \mathrm{E}-03$ & 5.49 & $3.24 \mathrm{E}-03$ & 5.48 \\
\hline 22.2 & 7.39E-02 & 5.49 & $1.35 \mathrm{E}-02$ & 5.49 & $5.03 \mathrm{E}-03$ & 5.48 & $2.53 \mathrm{E}-03$ & 5.48 \\
\hline 25 & $5.51 \mathrm{E}-02$ & 5.49 & $1.01 \mathrm{E}-02$ & 5.49 & $3.78 \mathrm{E}-03$ & 5.48 & $1.90 \mathrm{E}-03$ & 5.48 \\
\hline 28 & 4.17E-02 & 5.49 & $7.65 \mathrm{E}-03$ & 5.49 & $2.88 \mathrm{E}-03$ & 5.48 & $1.46 \mathrm{E}-03$ & 5.47 \\
\hline 30 & $3.52 \mathrm{E}-02$ & 5.49 & $6.47 \mathrm{E}-03$ & 5.49 & $2.44 \mathrm{E}-03$ & 5.48 & $1.24 \mathrm{E}-03$ & 5.47 \\
\hline 32 & $3.00 \mathrm{E}-02$ & 5.49 & $5.53 \mathrm{E}-03$ & 5.49 & $2.09 \mathrm{E}-03$ & 5.48 & $1.06 \mathrm{E}-03$ & 5.47 \\
\hline 36 & $2.25 \mathrm{E}-02$ & 5.49 & 4.17E-03 & 5.48 & $1.58 \mathrm{E}-03$ & 5.48 & 8.09E-04 & 5.47 \\
\hline 40 & $1.74 \mathrm{E}-02$ & 5.49 & $3.23 \mathrm{E}-03$ & 5.48 & $1.24 \mathrm{E}-03$ & 5.47 & $6.34 \mathrm{E}-04$ & 5.46 \\
\hline 45 & $1.30 \mathrm{E}-02$ & 5.49 & $2.44 \mathrm{E}-03$ & 5.48 & $9.38 \mathrm{E}-04$ & 5.47 & 4.84E-04 & 5.46 \\
\hline 50 & $1.01 \mathrm{E}-02$ & 5.49 & $1.90 \mathrm{E}-03$ & 5.48 & $7.34 \mathrm{E}-04$ & 5.47 & $3.81 \mathrm{E}-04$ & 5.46 \\
\hline 55 & 7.99E-03 & 5.49 & $1.52 \mathrm{E}-03$ & 5.47 & $5.90 \mathrm{E}-04$ & 5.46 & $3.08 \mathrm{E}-04$ & 5.45 \\
\hline 60 & $6.47 \mathrm{E}-03$ & 5.49 & $1.24 \mathrm{E}-03$ & 5.47 & $4.83 \mathrm{E}-04$ & 5.46 & $2.54 \mathrm{E}-04$ & 5.45 \\
\hline 65 & $5.33 \mathrm{E}-03$ & 5.48 & $1.02 \mathrm{E}-03$ & 5.47 & $4.03 \mathrm{E}-04$ & 5.46 & $2.12 \mathrm{E}-04$ & 5.44 \\
\hline
\end{tabular}

